\title{
ОСОБЕННОСТИ АДАПТАЦИИ МОЛОДЫХ СПЕЦИАЛИСТОВ К СПЕЦИФИКЕ ОРГАНИЗАЦИИ
}

Туливетров С.Н.

Рассматриваются особенности адаптации молодых специалистов научноисследовательских организаций оборонно-промышленного комплекса (НИООПК), находящихся на разных уровнях адаптачии. Полученные данные позволяют прогнозировать успешность прочесса адаптации молодых специалистов к специфике НИО ОПК и научно-исследовательской деятельности.

Ключевые слова: молодые специалисты, производственная адаптация, сочиально-психологическая адаптачия, челевая подготовка.

Анализ деятельности молодых специалистов НИО ОПК показал, что значительная часть выпускников базовых вузов, с которыми НИО ОПК имеет долгосрочные договоры о целевой подготовке специалистов в психологическом отношении, оказывается далеко не всегда профессионально пригодной. Несоответствие их индивидуально-психологических качеств, компетентностей специфике деятельности НИО ОПК, значительно затрудняет адаптацию молодых специалистов к специфике организации.

Наиболее оптимальным способом, повышающим эффективность адаптации молодых специалистов, является проведение целевой подготовки, учитывающей специфику работы в НИО ОПК.

Наше исследование было направлено на изучение личностных особенностей молодых специалистов организации, проявляющихся в период адаптации. Гипотеза исследования состояла в предположении, что существует сочетание социальнопсихологических особенностей личности, которое при определенных условиях может выступать фактором, детерминирующим успешную/неуспешную адаптацию человека в организации.

Степень адаптации (полная/частичная) может значительно различаться у молодых специалистов, прошедших целевую подготовку в организации до начала трудовой деятельности и молодых специалистов, не прошедших такой подготовки.

Объектом исследования явились 100 человек, вновь принятых на работу в крупную научно-исследовательскую организацию ОПК (ФГУП «ВНИИ «Градиент», г. Ростов-на-Дону). Все респонденты ростовчане, обоего пола, с высшим профессиональным образованием.

Эмпирический объект исследования включал две группы респондентов. Группа 1 - молодые специалисты (50 человек, из них 25 мужчин и 25 женщин), прошедшие целевую подготовку в подразделениях организации до начала официальной трудовой деятельности в возрасте от 23 до 30 лет, выпускники вузов с которыми предприятие заключило договоры о целевой подготовке молодых специалистов. 
Группа 2 - молодые специалисты (50 человек, из них 25 мужчин и 25 женщин) не прошедшие целевую подготовку до начала официальной деятельности на предприятии: в возрасте от 23 до 30 лет, выпускники вузов с которыми предприятие не имеет договоров о целевой подготовке молодых специалистов.

Методами исследования стали психодиагностика и метод статистической обработки результатов.

В исследовании были использованы: многофакторный личностный опросник Р.Б. Кеттелла (16-PF, форма А, стандартная); методика диагностики социальнопсихологической адаптации К. Роджерса и Р. Даймонда.

Результаты, полученные по методике Р. Кеттелла, позволили построить обобщенные личностные профили обеих групп испытуемых (см. рис. 1).

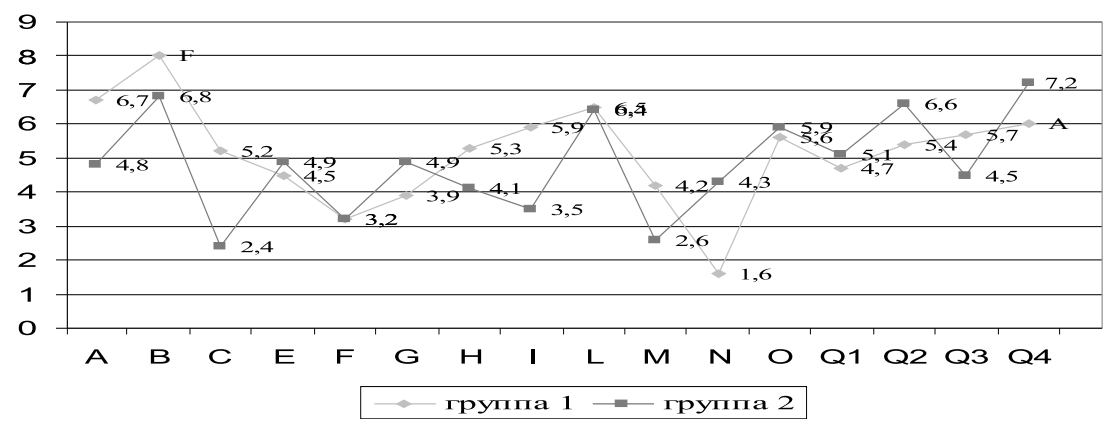

Рис. 1. Обобщенные личностные профили группы 1 и группы 2

Как видно из рис. 1, наиболее характерными личностными особенностями для респондентов группы 1 оказались следующие: высокие значения по фактору B; тенденция к высоким значениям по фактору А; низкие значения по фактору N; тенденция к низким значениям по фактору М.

Полученные данные позволяют выделить у респондентов группы 1 такие личностные характеристики: открытость, добросердечность, общительность. Они активны в устранении конфликтов, не боятся критики, испытывают яркие эмоции. У них наблюдается склонность к абстрактному мышлению, сообразительность и быстрая обучаемость, выдержанность, работоспособность. Они эмоционально зрелы, реалистически настроены, откровенны, доверчивы, благожелательны по отношению к другим людям. Они чаще стараются контролировать свои эмоции и поведение.

B группе 2 наиболее выраженным оказался другой набор факторов: B+ , L+ , $\mathrm{O}+, \mathrm{Q}_{2}+, \mathrm{Q}_{4}+$, C- , M- , F- . Полученные данные свидетельствует о том, что респондентам группы 2 присущи: эмоциональная неустойчивость, чувствительность, низкий уровень толерантности в стрессовых, фрустрирующих ситуациях. Им более свойственны осторожность, практичность, неразговорчивость, пессимистичность, высокий уровень тревожности. Они склонны к интроверсии, замкнутости, 
одиночеству, ригидности, вместе с тем показывают высокую степень подвижности психических процессов: стремятся к самостоятельности и самодостаточности, порой скептически относясь к ценностям других людей. Наблюдается тенденция к проявлению бескомпромиссности, излишней подозрительности, недоверчивости и внутренней настороженности.

Были изучены особенности социально-психологической адаптации обеих групп с помощью методики К. Роджерса и Р. Даймонда (см. таблицу 1).

\section{Таблица 1}

\section{Уровень социально-психологической адаптации групп 1, 2} по методике К. Роджерса и Р. Даймонда

\begin{tabular}{|c|c|c|c|c|}
\hline \multirow[b]{2}{*}{ Факторы } & \multirow{2}{*}{$\begin{array}{c}\text { 3начимость различий, } \\
\text { (двухвыборочный } \\
\text { тест Z-тест), a }\end{array}$} & \multicolumn{3}{|c|}{ группы } \\
\hline & & $\bar{X}$ & $\begin{array}{c}\text { Группа } \\
1\end{array}$ & \begin{tabular}{|c|} 
Группа \\
2 \\
\end{tabular} \\
\hline Адаптивность & 0,051 & 49,7 & 69,4 & 30,0 \\
\hline Дезадаптивность & 0,001 & 50,3 & 30,6 & 70,0 \\
\hline Принятие себя & 0,042 & 72,8 & 84,8 & 60,7 \\
\hline Непринятие себя & 0,005 & 42,0 & 71,6 & 12,4 \\
\hline Принятие других & 0.001 & 27,3 & 15,2 & 39,3 \\
\hline Непринятие других & 0,001 & 58,0 & 28,4 & 87,6 \\
\hline Эмоциональный комфорт & 0,005 & 57,6 & 69,5 & 45,7 \\
\hline Внутренний контроль & 0.006 & 51,6 & 57,1 & 46,0 \\
\hline Внешний контроль & 0,052 & 48,5 & 42,9 & 54,0 \\
\hline Доминирование & 0,001 & 69,8 & 54,6 & 84,9 \\
\hline Подчинение & 0,001 & 30,3 & 45,4 & 15,1 \\
\hline Наличие депрессии & 0,001 & 44,8 & 26,4 & 63,2 \\
\hline Отсутствие депрессии & 0,441 & 55,2 & 73,6 & 36,8 \\
\hline
\end{tabular}

Данные свидетельствуют о том, что вся выборка респондентов по уровню адаптации может быть оценена в равной степени как адаптивная (49,7 \%), так и дезадаптивная (50,3 \%). В большинстве случаев респонденты принимают себя (72,8\%) и не принимают других (58,0 \%). При этом у них чаще всего присутствует эмоциональный комфорт $(57,6 \%)$, развит внутренний контроль $(51,6 \%)$ и стремление к доминированию $(69,8 \%)$.

У респондентов группы 2 более развитым оказался внешний контроль за своими действиями (54,0\%), а у респондентов группы 1 - внутренний $(57,1 \%)$. И те, и другие склонны скорее доминировать в отношениях с другими людьми (соответственно, 84,9\% и 54,6 \%), чем быть ведомыми (соответственно, 15, 1 \% и 45,4 \%). Респонденты группы 2 чаще испытывают депрессивные чувства, настроение, нежели респонденты группы 1; соответственно 63,2 \% и 26,4 \%.

На основе данных использованных методик были выявлены личностные особенности и качества социально-адаптированного и социально-неадаптированного специалиста в организации (таблица 2). 
Таблица 2

\section{Личностные особенности и качества социально-адаптированного} и социально-неадаптированного специалиста в организации

\begin{tabular}{|l|l|}
\hline $\begin{array}{l}\text { Социально-адаптированные спе- } \\
\text { циалисты }\end{array}$ & $\begin{array}{l}\text { Социально-неадаптированные специ- } \\
\text { алисты }\end{array}$ \\
\hline $\begin{array}{l}\text { 1. Адекватная самооценка, незави- } \\
\text { симость }\end{array}$ & $\begin{array}{l}\text { 1. Заниженная самооценка, склонность } \\
\text { к конформизму }\end{array}$ \\
\hline $\begin{array}{l}\text { 2. Принятие ответственности за } \\
\text { свою жизнь, свои поступки }\end{array}$ & $\begin{array}{l}\text { 2. Перекладывание ответственности на } \\
\text { других, или на внешние обстоятельства }\end{array}$ \\
\hline 3. Высокая мотивация достижения & 3. Низкая мотивация достижения \\
\hline 4. Общительность & 4. Замкнутость \\
\hline 5. Доминирование в отношениях & 5. Подчиненность \\
\hline 6. Уверенность в себе & 6. Неуверенность в себе \\
\hline 7. Умение планировать свою жизнь & 7. клонность к отсутствию сопротивления \\
\hline $\begin{array}{l}\text { 8. Отсутствие трудностей в общениии } \\
\text { и склонность к сотрудничеству }\end{array}$ & $\begin{array}{l}\text { 8. Трудности в общении и сотрудни- } \\
\text { честве }\end{array}$ \\
\hline $\begin{array}{l}\text { 9. Отсутствие депрессивных состо- } \\
\text { яний }\end{array}$ & $\begin{array}{l}\text { 9. Склонность к депрессивным или суб- } \\
\text { депрессивным состояниям }\end{array}$ \\
\hline
\end{tabular}

Исследование позволяет сделать некоторые выводы.

1. Молодые специалисты, не прошедшие специальную целевую подготовку в организации, испытывают значительные трудности в адаптации к работе, и к организации в целом. После прохождения целевой подготовки в организации они быстрее адаптируются к организации, процесс их адаптации происходит менее травматично и за более короткий срок.

2. Выявлены социально-психологические критерии адаптированности молодого специалиста. Выделенные критерии могут использоваться в целях составления прогноза адаптации молодого специалиста в НИО ОПК.

\section{Литература}

1. Большая энциклопедия психологических тестов. - М.: Изд-во Эксмо, 2005.

2. Дружилов С.А. Профессионализм человека и критерии профессиональной адаптации. Объединенный научный журнал. - М.:ТЕЗАУРУС, 2003. - № 1. - С. 15-16.

3. Маслов Е.В. Управление персоналом предприятия. - М.: ИНФРА-М; Новосибирск: НГАЭиУ, 2001.

4. Потоцкий М.Ю. Раздел «Человеческие ресурсы в третьем тысячелетии. Тенденции современного управления персоналом». - М.: ГроссМедиа, 2004.

5. Управление персоналом / Под. ред. Т.Ю. Базарова, Б.Л. Еремина. - М.:ЮНИТИ, 2000.

6. Управление персоналом организации / Под. ред. А.Я. Кибанова. - М.:ИНФРА, 2003.

7. Фонарев А.Р. Формы становления личности в процессе ее профессионализации // Психология работы с персоналом в трудах отечественных специалистов: Хрестоматия / Под ред. Л.В. Винокурова. - СПб.: Питер, 2001. 